\section{Taking home-ranges into account for Mediterranean MPAs could offer increased recovery benefits}

Marine protected areas (MPAs) are a common fisheries management tool that relies on the assumption that species protected within a spatially-explicit area are allowed to recover and later "spill over" the boundaries of the MPA where they may be harvested. By fully protecting an MPA, species inside will grow and reproduce a steady supply of "spilled over" fish to be harvested. But how large of an area should you protect at a minimum to offer this benefit?

Previous studies have shown that MPAs should be sized at least twice as large as the target species' home range, i.e. where the species spend the majority of their time. Home ranges here are defined as the area in which "an individual spends $95 \%$ of its time and engages in routine activities, such as foraging and resting." This excludes reproductive and developmental migrations. If you create a list of species that your MPA aims to protect, and then rank the species from largest home-range to smallest, your MPA should be at least as large (ideally, twice as large) as the home range of the species at the top of this list.

The authors show that in the case of fully-protected MPAs in the Mediterranean Sea, species have higher densities in MPAs when the size of the MPA is at least twice the size of that species home range (see figure below). In this case, the ideal MPA should be at least $3.6 \mathrm{~km}^{2}$ to adequately protect targeted species. Of the Mediterranean's fully-protected MPAs, only $24.5 \%$ are larger than double the largest home range of a targeted species.

New MPAs should be designed with home ranges as a priority from the start, and existing MPAs may offer better protection by increasing boundaries to encompass the home ranges of targeted species.

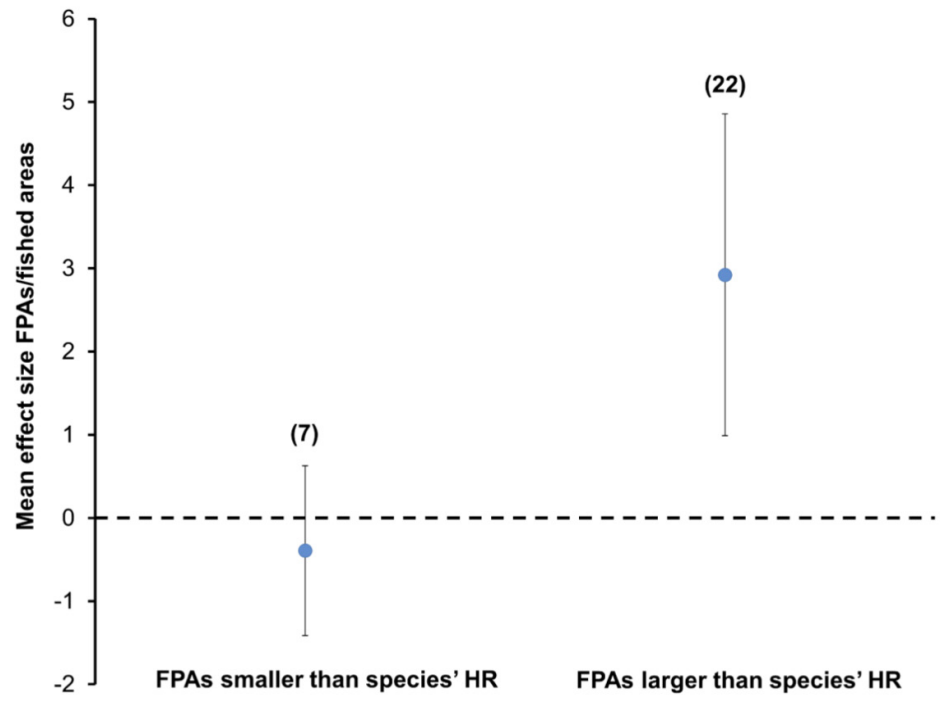

Figure 3. Effect of fully protected area on fish density as the mean of effect sizes across species calculated between the fully protected areas (FPAs) and fished areas in fully protected areas smaller and larger than species home range (HR). A positive effect size indicates a higher density of a species within the FPA relative to the fished area. The graph displays the weighted ratio and $95 \%$ Confidence Interval $(\mathrm{Cl})$ in and out of the fully protected areas.
This is a summary of: Linking home ranges to protected area size: The case study of the Mediterranean Sea

Accessible at: https://marxiv.org/26knw

Authors: Antonio Di Franco, Jeremiah G. Plass-Johnson, Manfredi Di Lorenzo, Bruno Meola, Joachim Claudet, Steve Gaines, Jose Antonio Garcia-Charton, Sylvaine Giakoumi, Kirsten GrorudColvert, Carlos Werner Hackradt, Fiorenza Micheli, Paolo Guidetti

Added to MarXiv: March 2018

Published: Biological Conservation, 2018

Suggested Citation: Taking home-ranges into account for Mediterranean MPAs could offer increased recovery benefits OCTO (2018). DOI: 10.17605/OSF. IO/A8BZP

See more MarXiv summaries at https://www.marxivinfo.org/ summaries

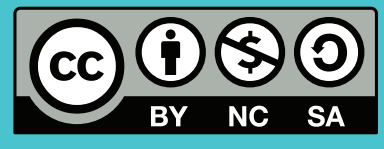

MarXiv is an ОстO Initiative
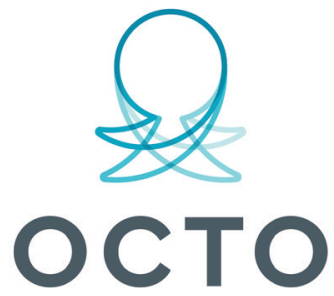

OPEN COMMUNICATIONS FOR THE OCEAN 